\title{
Politics of Urban Development in India
}

\author{
Dr. Purobi Sharma \\ Associate Professor, Department of Political Science, Cotton College, Assam,India
}

\begin{abstract}
Urbanization as a part of development process is a major concern for policy makers in a country. Strategies are needed to create a suitable urban landscape. Public policy towards urban development incorporates a wide range of issues - land, economy, infrastructure, environment, management and many others .Coordination of issues is a major task for urban development management authorities. In Indian context political leadership has been provided on an adhoc and piecemeal basis with little consideration of integrated approach. .Urban planning in India till now is facing great challenges of political dominance and considerations. In this paper an enquiry has been made to show the top down policy statements to explore the urban policy initiatives as politics of urbanization process. However, the assessment of the situation in a comprehensive way reveals that the urban local bodies at the ground level are not accorded an effective functional status despite the legal provision. With changing situation, the intervention becomes much more complicated. The objective of the paper is to highlight the fact that in the context of the present situation, India has to address the issues of Decentralization, Community Welfare and Capacity Building in Development Management Paradigm.
\end{abstract}

Key words: policy, centralization, allocation, piecemeal, market, planning.

\section{Introduction}

Urban development as a reflection of overall development process cannot remain outside the purview of the political system of the country. Accordingly the politicians and the civil servants in India take the most active part in the policy formulation process in the urban context. However, no direct declaration was made about the intention and purposes in the constitution of India in regard to the aims and objectives of urban development in the country. The lack of explicit constitutional status of cities and towns were explained in terms of "anti-urban bias" at the higher level of policy formulation ${ }^{1}$ (Raheja, 1973).During the initial state building and reconstruction process the role of cities were not emphasized. The Gandhian model stressed on self- reliant village and Nehruvian model was concerned with the growth of a modern society as a part of nation building process. The lack of consideration of urban issues in the early years of development planning in India can also be seen as the nationalist legacy of developing villages ${ }^{2}$ (Batra, 2012).

The demarcation of functional domain of federating units in India under the seventh schedule of the constitution gives the picture of involvement of the central and the state governments. The scheme of allocation of functional responsibilities between the union and the state government give the states the responsibility of legislating on the subject of urban development as its vital aspects like land development, water supply, public health, sanitation have been included in the state list. The power of determination of industrial location, however, rests on the Union Government, which plays a major decisive role in the growth and development of cities and towns. Centre has taken steps in urban legislation, in initiating several schemes and programmes to promote decentralization and empowerment of urban local governments. However, the significant focus on the issue was made in 1985 with the creation of Ministry of Urban Development, in the Govt. of India. Prior to that, changes were made in the urban development management scenario with the creation of Slum Improvement Boards, Housing Boards, Integrated Urban Development Programme, promulgation of Urban Land Ceiling and Regulation Act and creation of Housing and Urban Development Corporation. In formulating such policies it must be recognized that the performance of macro economy can be improved by improving the productivity of the urban sector ${ }^{3}$ (Agnihotri, 1995). An important consideration is that the inexorable demographic surge in urban India is fueled by the growing disparity between rural and urban per capita income. From near parity in 1950 , in the 1990's the ratio of urban per capita income to rural per capita income was nearly $4: 1$. As per the $66^{\text {th }}$ round of National Sample Survey (NSS) for the period July 2009 - June 2010, the divide has accentuated to approx 9:1.

\section{Centralized policy}

The central government's involvement in the urban development issues since independence has been expanded due to ever increasing importance of development issues and rapid urbanization. The role of the central government in the field of urban development touches some vital questions of state autonomy and power disputes between federating units. The direct relationship between the union and the cities and towns is usually 
not favored by the states, as it goes against the principle of local self government in urban areas. In this context the observation made by Bhagwan Das Raheja is noteworthy: Cities and towns, as part of the states are an integral part of the nation. Their administrative problems are no longer isolated and cannot be confined to their municipal limits. Since the cities are governed and administered by the states, they are subject to the same restraints and regulation in the fundamental laws as apply to the state governments ${ }^{4}$ (Raheja). In fact, urban development is a major component of overall development planning and in the developing societies; urban development planning is recognized as part of the overall planning of the country. Urban planning and development legislation serves as the basis for determination of system of urban government, management and regulation of development process. However urban planning and development laws of different states of India Union vary according to the specific pattern and conditions of urban development in each state. Moreover, in each state, multiple urban related issues have given birth to proliferation of laws on the subject. Since each law tries to create its own planning, development and management framework, the outcome is the creation of numerous development authorities and state departments. In the Indian context, the major problem that has emerged is that of co-ordination among these multiple authorities. Despite being a part of a larger government, created with the objective of promoting the planned growth each authority thinks in its own way, acts in its own way leading to mismanagement and confusion ${ }^{5}$ (J.K. Gupta).

In regard to the implementation part, the laws have created the situation of bureaucratization of urban development in which long and complicated rules regulations and procedures have alienated management process from the people ${ }^{6}$ (Gupta). The urban development agencies are the centres of bureaucratic control which initiate complicated and time consuming procedures for obtaining approval for development activities ${ }^{7}$ (Gupta).

\section{A paradoxical situation}

In this general framework of politico - administrative system, a specific role is played by the urban local self government or the city government such as the municipal corporations, municipal boards, and town committees. With the coming into force of $74^{\text {th }}$ Constitutional Amendment Act, 1992 the municipal governments have received a constitutional recognition for the first time since independence. The Act stands for the much needed structural changes in municipal government which was subjected to strict control of state bureaucracy due to almost regular and prolonged supersession of urban local bodies. The changes provided by the Act have fulfilled the demand for municipal reforms in the significant areas of urban functions, creation of planning committees in the district and metropolitan areas, appointment of state finance commission and state election commission and assurance to political existence of urban local bodies.

The Act thus ensures a firm constitutional basis for political decentralization of urban development management process. It touches vital issues of the subject such as, preparation of development plans covering the urban situation in a comprehensive way and making arrangements for sorting out institutional conflict in providing infrastructure. The decentralization initiatives taken by the Act and the spirit of economic liberalization of macroeconomic policies are meant for encouragement for new roles and the involvement of the private sector in infrastructure development. The scope of public - private partnership in urban local government sector and participatory management of development plans are emerging as major issues of urban development management process at the present juncture. Other important issues raised by the Amendment Act are the spirit and willingness of the states to implement the Act with clear identification of functional jurisdiction of institutions and the capacity of urban local bodies to carry out the responsibilities with sound financial, managerial and technical skill ${ }^{8}$ (Dutta, 1995).

A paradoxical situation is emerging in the paradigm of urban development management. The 74th constitutional amendment act (CAA) envisaged creation of vibrant urban local bodies empowered with funds, functions and functionaries, where as in the present context urban governance is characterized by fragmentation of responsibility, incomplete devolution of functions and funds, unwillingness to render municipal autonomy, adherence to outmoded methods of property tax and reluctance to levy user charges. State governments continue to take decisions on such matters as rates of user charges, property tax, octroi, role of parastatals in water supply and sanitation services, etc., with little reference to the ULBs that are affected by these decisions. Far from strengthening the constitutional role of the elected ULBs, such developments only reinforce the perception that ULBs are subordinate entities under the day-to-day control of the state governments, beholden to them not only for the development of the cities but often for their very survival. There appears to be a lack of confidence that many of the ULBs are capable of meeting their obligations as institutions of local self governance. In the present set up, initiatives for local developmental activities rarely come from the ULBs. 74th CAA can be realized only through the implementation of various institutional, financial and administrative reforms which will pave the way for enhancing service.

Experience shows that functional autonomy becomes a reality only when it is accompanied by financial independence. State governments, therefore, need to strengthen the autonomous functioning of the ULBs through positive measures, and in particular, has to ensure their financial self-reliance 


\section{Political perspectives}

Urban development policy in India is to be understood in terms of several policy statements of the government instead of relying on a single set of policy declaration. Various suggestions as policy guidance's have been made from time to time in the light of rapid urbanization. The National plan documents, recommendations of different committees an commission set up by government, governments policy on slums and town improvement, various schemes, the Urban Land Policy, Housing Policy, Policy on urban environment, infrastructural arrangements serve as important indicators of the government of India's perspective of urban development. Such a range of policy contents reflect the highly complicated character of urban development process and interrelationships between various associated elements.

In searching for major components of an urban development policy in India, it can be easily accepted that it must be conducive for economic development of the country. In this context, it is recognized fact that the urban sectors have to play a positive role in bringing backward regions to the path of economic development and have to provide a sound infrastructural basis for urban environment and activities. The process of urban development manifests the socio-cultural, economic-physical and political-administrative dimensions of the urbanization pattern in the society. As identified by an expert involved in the urban development activities in the field:

The basic objective of urban development activity is to achieve balanced development for all aspects of urban life, physical, social, economic in a comprehensive manner. The sectors that are of direct importance for the local authorities and development authorities include physical infrastructures like water supply, drainage and sanitation, solid waste management, transport, shelter, and also the social infrastructures like parks and community open spaces, health, education, security and community development for urban poor ${ }^{9}$ (Som, 1995).

The issues related to urban development process therefore are significantly related to the development Management. An efficient management system for the urban development can be envisaged as a tool in channelizing the process in a desired manner particularly in the physical aspects ${ }^{10}$ (Banerjee). For a student of urbanization pattern in India it is not difficult to identify the intended and unintended pattern of urban development as it is virtually related to urban life. The growth of slum and squatter settlements, unauthorized use of land, encroachments, violation of Master plans are some of the physical aspect unintended urban development process in the cities of developing societies. Therefore, urban policy administration system has to be a major component of urban development policy, which, as we shall see now is not comprehensively highlighted in urban policy declaration of government of India. From the survey of Plan documents and other related policy declaration of government of India, the issues taken up by the government of India can be classified into following ranges.

Urban land development; urban infrastructure ; policies related to improvement of small and medium towns along with the growth of big cities; Slum improvement; Remedy for pathological issues; Regional development; Urban development as an adjunct to economic development; the identification of functional characteristics of the city in relation to its hinterlands and in case of primate character the relationship with the region of which it is a part; town planning; devolution of funds and revitalization of civic bodies. All these aspects have been echoed in varying degrees in the government of India's perspectives of urban development.

\section{Thrust areas in Development Planning}

At the initial stage of India's planned development process, the urbanization pattern was almost left out without any proper guidance and rural development was the most emphasized sector. However, the growing importance of the urban sector was recognized by the planning commission in securing speedy economic development in a development in a developing society like India. The complementary role of urban and rural sectors began to be emphasized so that neither a situation of "unhealthy and problem oriented urban development" emerged nor a "stagnant and self retarding" rural development is created ${ }^{11}$ (VKRV Rao). The assessment of the nature of attention accorded to urban development sector since the First Five Year Plan fulfill two significant purposes of the study of urban development policy in India. First, it reveals the growth and continuity of urban policy framework in its historical perspective. Such assessment focuses on the gradually changing scenario in the urban sector and the need of a dynamic approach of the government thereon. Second, the understanding of the role of Five Year Plan in urban development reveals the necessary inter-linkages between the country's development process and the urban development particularly from the point of view of economic programs and policies. It can be easily perceived that in the ultimate analysis in a developing society urban development process has a direct bearing on the process of social change and economic development. The issues recognized by the Planning Commission during different plan periods are shown below:

The First Five Year Plan (1951-56) viewed urbanization "as proliferation of labour camps caused by rural to urban migration". The consequence of urbanization was acute shortage in housing sector and therefore it recommended control over land speculation and inflation in land prices. From the point of view of institutional management, the plan recommended utilization of urban local bodies. There must be a vital relationship 
between the government and urban local bodies in fulfilling demands for services in the urban areas. The plan period was significant for institution building through new organization like Ministry of Working and Housing, National Building Organization, Town \& Country Planning Organization and Housing Board.

The Second Plan (1956-61) emphasized industrial growth within the framework of overall development plans in each state and region. For the management purposes the preparation of Master Plan and the constitution of Delhi Development Authority initiated a new trend in urban planning and its implementation process. The Third Five Year (1961-66) contributed towards formulation of comprehensive development plans for major cities and their surrounding areas. It initiated serious thinking on sound urban development plans for rapidly growing cities and industrial centers. The Central Government provided 100 percent financial assistance for implementation for such plans. Preparation of Master Plans for metropolitan cities and subsequent legal provisions for implementation by Development Authority was also initiated.

The Fourth Plan (1966-71) recommended a regional approach to the problem of urban development with restructuring of local areas. It laid emphasis on the role of a strong and recognized local administration. The programme of slum clearance and environmental improvement in slums was launched.

The remarkable initiative in institution building was taken through the organization of the Housing and Urban Development Corporation of India (HUDCO). As a techno-financial institution, it renders financial and technical assistance to housing and infrastructure sector and other urban development activities in metropolis as well as in small towns. The Fifth Plan (1974-79) enlarged the objectives of urban development and some positive steps were recommended to expand the range of urban development activities. The steps included several urban development plans such as launching of Integrated Urban Development Programme for large cities, augmentation of civic services in urban centers, to improve the condition of urban infrastructure development of small towns to lessen the growing pressure of migration to bigger towns etc. Urban Land Ceiling and Regulation Act, 1976 was enacted during the plan period.

The Sixth Plan (1980-85) identified important components of Urban Development Plan in a comprehensive perspective:

(a) The planned and integrated development of small and medium towns along with showing down of growth of big metropolis;

(b) Revitalization of civic bodies;

(c) Reforms of municipal tax systems and municipal administration in general;

(d) Improvement of slums;

(e) Regular devolution of funds from state governments for municipal services.

The important policy guidelines were: Identification of regional urban systems according to their economic, climatic, geographical and transportation characteristics. In planning urban development, the regional context of towns and cities is to be considered. Secondly, urban development plans must be supportive of the economic development of the region, state of the country. Thirdly, the plan emphasized the need investment in urban development. During the Sixth Plan period the task forces (1983) appointed by the planning commission submitted reports which contained valuable guidelines for housing and development.

The Seventh Plan period (1985-90) was remarkable for appointment of National Commission on Urbanization (1988) which articulated urban policy perspectives at the national level. The Seventh Plan reasserted the policy concerns expressed in the Sixth Plan. Accordingly, the need of balanced relationship between the regional development and urban development was reaffirmed. The plan document reviewed the policy context up to Sixth Plan period and revealed that urban policies mainly addressed problems like housing, slum clearance, slum improvement and upgradation, preparation of Master Plan, development of small and medium towns, strengthening of municipal civic administration etc. The Seventh Plan initiated programmes for urban poverty alleviation and accordingly launched two major centrally sponsored schemes know as Urban Basic Services (1986) and the Nehru Rozgar Yojana (1989). The plan document reveals that external assistance was a major source of finance during the Seventh Plan period.

Thrust areas in the Eighth Five Year Plan (1992-97) consist mainly of more effective implementation of the strategies adopted during the Seventh Plan and partly in formulation of new strategies. In the light of articulation of urban policy concerns by National Commission on Urbanization, the Eighth Plan emphasized resource mobilization through change in funding pattern by allowing private sectors in providing urban infrastructure. It stressed on legal, financial and organizational measures for effective urban development. For the management of urban development, the plan focused on following aspects: A decentralized framework of urban government with necessary participation of local communities and opinion leaders in planning, implementation and monitoring of urban development programmes is another prerequisite for the success of urban development strategy. In addition to the enactment of the Nagar Palika Bill, which is a necessary but not a sufficient condition for efficient urban development, other normal management improvement schemes, including national and local level training programmes and delegation of administrative functions and 
responsibilities, will help the process. In case of large city government, shift from one centralized authority to a system of smaller area - based committees may be more effective in delivery of urban services.

Ensuring continuity of the important programmes of the previous plan, the Eight Plan launched new programmes with a specific view to generate employment for the poor in the urban sectors. The Urban Basic Services Scheme, 1986 was revised as Urban Basic Services for the poor (UBSP). The revised programme was based on the earlier scheme of UBSP. It is sponsored by the Central Government and shared by state government on matching basis. For the management purposes the scheme has been included within the purview of Urban Local Bodies. The scope for Non Governmental Organizations was also recognized. The Plan document revealed its concern for the need of an organizational system for monitoring and evaluation of implementation process. The scheme of Nehru Rozgar Yojana, 1989 was expanded to include three other schemes, namely The Scheme of Urban-Micro Enterprises (SUME), the Scheme of Urban Wage Employment (SUWE) and the Scheme of Housing and Shelter Upgradation (SHASU). A clear cut management system for N.R.Y. scheme was provided at the state, district and town or city level. State Urban Development Agency, District Urban Development Agency and Urban Local Bodies are entrusted with monitoring responsibilities at respective levels.

The urban development objectives of the Planning Commission at that situation focused on: Development of urban areas as economically efficient, socially equitable and environmentally sustainable cities; Accelerated development of housing, particularly for the low income groups and other disadvantage groups; Development and up gradation of urban infrastructure services; alleviation of urban poverty and unemployment; Promoting efficient and affordable mass urban transportation systems in metropolitan cities; promoting private sector participation in the provision of public infrastructure and of the community and NGOS in urban planning and management of specific components of urban services.

During the Ninth Five Year Plan (1997-2002), India crossed the fifty years of Independence which called for a whole new set of development measures. The main focus was on attaining objectives like speedy industrialization, poverty reduction, full-scale employment, human development, self reliance on domestic resources etc. In order to overcome the deficiencies and to approach the desirable urbanisation pattern, an outlay of Rs.1,250 Crores was provided for the "Urban Development" sector in the Ninth Five Year Plan, for implementing various programmes. The expenditure during the Ninth Five Year Plan for the sector "Urban Development" was estimated to be Rs. 2,215 Crores, which is nearly double the Ninth Plan outlay. To improve the economic and physical infrastructure and also to provide essential facilities and services in the urban areas, the Ministry of Urban Development and Poverty Alleviation has taken a number of Central and Centrally Sponsored Schemes. These Schemes have made some progress in the quality of life in the urban areas though the magnitude of urbanization demands faster and large interventions in the urban areas.

The $10^{\text {th }}$ five year plan (2002-2007), recognized the role of urbanization as key determinant of economic growth. It focused on several issues related to urban growth and its impact in the country. It also recognized the good urban governance based on adequate policy and legal frameworks, human skills, a sound revenue base and accountability. It aimed to achieve a substantially higher coverage of cities in need of infrastructural upgradation. The Tenth Plan also observed that the central assistance for infrastructure must be made conditional on sector reforms, in particular better standards of service and the collection of user charges. Another issue before tenth plan was poverty reduction in urban areas. In this context, it also focused on schemes for the urban poor. Such schemes aimed at well defined and coordinated services for slum populations. Institutional Financing of housing was also emphasized. However, the most striking problem recognized by tenth plan was strengthening of urban local bodies through building of sound financial system. In short, the major thrust areas were:

- Upgradation of infrastructure.

- Raising institutional capabilities.

- Public-Private partnership in service delivery.

- Increased housing activities particularly for the economically weaker sections and the low income category.

The Eleventh Five year plan, (2007-2012), mainly focused on the economic growth as it can be considered to be the key indicator of urbanization which may lead to the overall development. The strategy adopted for urban development during this plan period involved the following:

- Strengthening urban local bodies through capacity building and better financial management.

- Increasing the efficiency and productivity of cities by deregulation and development of land.

- Dismantling public sector monopoly over urban infrastructure and creating conducive atmosphere for the private sector to invest.

- Establishing autonomous regulatory framework to oversee the functioning of the public and private sector.

- Reducing incidence of poverty. 
- Using technology and innovation in a big way.

However it has been seen that the capacity building interventions taken in this plan have been wide ranging and comprehensive in terms of the components addressed and in a major part have focused on provision of technical assistance, training and knowledge support to enable implementation of programmes and related components. But, the absorptive capacity of the ULBs were limited and beset with inherent demand side constraints. During this plan period JNNURM, launched as a Mission mode project to build the infrastructure deficit in the 65 larger Cities and other small and medium towns, took a holistic view of capacity development but the absence of the right eco-system and the deficiencies on the supply side have led to sub-optimal achievement of intended objective.

The Planning Commission formulated a Working Group on capacity building in the recently adopted Twelfth Five Year Plan for the period 2012-2017 and this issue has been given the foremost attention here. According to it a favorable enabling environment for capacity building has to be created through the right mix of policy prescriptions with financial incentives for result oriented implementation of activities. This would include a capacity building strategy at the state and ULB level which will comprise an organisational development strategy, a human resource development strategy as well as an institutional and legal framework at the state and ULB level. The capacity building programme should further be advocated and its activities at the center, state and ULB level should be converged. Moreover the TwFYP has also aimed to strengthen supply side institutions and the Civil Society Organisations to meet the emerging demand and make them useful partners in governance and service delivery respectively.

The objectives enumerated in the plan documents particularly since the seventh plan period reflect the growing trends of directing urban development issue towards promoting regional development and involvement of private sector in providing urban infrastructure. The issue of regional development as a part of total development of the country under the programmes of Five Year Plans was reflected in "area development" with a focus on spatial implications. The plans and programmes initiated as part of this in the urban areas are metropolitan area development programmes, development of small and medium towns and urban community development projects ${ }^{12}$. (S.C. Gupta, 1980) The issue related to privatization of urban infrastructure is receiving the attention of the state governments in varying degrees. The 11thPlan clearly states "increasing the efficiency and productivity of cities by deregulation and development of land" and "dismantling public sector monopoly over urban infrastructure and creating conducive atmosphere for the private sector to invest". The fact remains that the faster rate of urbanization in the decade ending 2011 may unleash new challenges for planners as well as policymakers.

\section{Task Forces: A departure from the past}

The appointment of the Task Force on Housing and Urban Development in 1983 was a major step towards determination of policy framework for urban issues. The task Force dealt with four major issues, i.e., Planning of Urban Development on the basis of past and present trends in urbanization in India; second, financing of urban development particularly the sector of infrastructure covered by municipal originations; third, in management of urban development, fourth, slum improvement and shelter for urban poor with full involvement of the people. The nature of management of urban development was criticized for proliferation of development agencies and forwarded the case for strengthening municipal bodies with a new approach towards finance, personnel management, institutional framework and co-ordinations of development function. The urban policy and programmes pursued by the government till 1980s was criticized on the ground that the basic approach taken towards urban development was wrong. The following criticism is self explanatory of the situation:

Policy and programme interventions have been half-hearted, loosely co-ordinated and even counterproductive; spatial considerations have never received the attention they deserve. Policy has been halfhearted in as much as a few of the points at which governments might intervene to manage urbanization and affect its course and direction have been properly tackled. It is uncoordinated in as much as national planning tends to be in terms of sectoral outlays, while urban planning has been mainly linked with physical layouts. It is counterproductive in as much as the effort has been to divert, retard, or stop urban growth and in particular to inhibit the expansion of metropolitan cities ${ }^{13}$.

Clearly enough the Task Force was in favour of urban development as an adjustment to economic development with a modified system of urban government, urban finance and urban management.

With the creation of first ever Ministry of Urban Development (MoUD) in the Government of India, the year 1985 marked the beginning of a new direction on urban development and related issues in India. This was a result of growing focus on urbanization and related issues which emerged due to appearance of global and Indian focus on the subject since late seventies. These include 'human settlement focus of UNCHS' emanating from International conference on Human Settlements (Vancouver) in 1977 followed by preparatory work on 
Habitat Agenda and UNICEF, World Bank UNDP, UNEP and UNESCAP initiatives on urban poor, sites and services, environment and urbanization for regional development etc.

Within India as well, the compelling factors covered creation of Slum. Improvement Boards, Housing Boards, Initiation of IUDP (Integrated Urban Development Programme) for towns with population three lakhs and more, UCD (urban community Development) Project at Hyderabad and Indore, promulgation of urban Land Ceiling and Regulation. Act (ULCRA) of 1977 and creation of HUDCO (Housing and Urban Development Corporation) in 1977. This combined with unprecedented and highest ever urban growth (46.2 per cent) since independence during 1971-81 created a pressure group to promote importance of urban issues. These events paved way to a turning point on urban development which took a tangible shape in 1985.

As a first major step in this direction, MoUD in 1985 created National Commission on Urbanisation (NCU) to have a holistic view on urban sector issues in the country and suggest a generic agenda for suitable follow up and discussion at policy level. These deliberations contributed to interstate dialogue and consensus which finally emphasized on 'Power to People' / 'Decentralization' and 74th Constitution Amendment Act was promulgated accordingly. Statement of objects and reasons of the bill which was passed as 74 CAA emphasized on a need to make ULGs a 'vibrant democratic unit of self government'. At the same time a range of fiscal, institutional and planning related actions were also taken which inter-alia included creation of National Housing Bank (NHB), Promulgation of Housing and Habitat Policy (1988) and follow up activities on 74th CAA and a range of public sector schemes and programmes aiming at infrastructure, services, poverty alleviation and specific reforms in the sector.

The first turning point has also covered a journey of good governance in the urban sector to ensure further decentralization, accountability, transparency and civic engagement. Wards committees, Area Sabhas, accounting and budgeting reforms, IT application have been initiated at different levels of application. This has shown a tripartite consensus between centre, state and ULGs to have synergy and convergence for more effective administration of urban development in Indian cities and towns.

\section{Towards formulation of National Urban Policy: National Commission on Urbanization}

The appointment of National Commission on Urbanization in 1983 was a major step in reviewing the urban situation with a positive outlook about the role of the cities in the process of country's economic development. The voluminous Report of the commission submitted to the government of India in 1988 provided basic guide lines for the formulation of goals of National Urban Policy in the context of emerging socioeconomic imperatives of development both at the macro and micro level. At the macro level, it stressed on the identification of urbanizational hierarchy of cities as generators of Economic Momentum, further classified as National Priority Cities and state priority cities. Spatial Priority Urban Regions with potential economic opportunities were identified as core areas to increase economic opportunities. M.N. Buch observes that the proposals of N.C.U. on city size and the settlement hierarchy are radical departures from the past as it has tried to explain growth potentialities of regional towns, capital cities, urban centre's of backward regions in terms of infrastructure investment and township development in the context of industrial and business investments ${ }^{14}$. (Buch) Commenting on low volume of 3.4\% of the total plan outlay allocated to urban sector, it recommended that the plan allocation to urban development sector should be at least $8 \%$ of the total plan outlay. At the micro level, the N.C.U. emphasized guided land management in correct perspective as a resource and its optimised use under changing circumstances. The Commission highlighted environmental degradation in cities and towns and stated that "we have spoken much of urban patterns and spatial planning, it is time we turn our attention to the people who inhabit our towns and cities ${ }^{15}$. The Commission recommended consideration of the aesthetic and visual impacts in land use planning. Charles Correa, the Chairman of the N.C.U. emphasized the aspect in the following word:

In the past, the relationship between buildings and cities was analogous to those of spare parts to machines. Today our city centre's are beginning to look like a collection of spare parts, with no one having the slightest idea of - nor responsibility for - what the whole machine is about ${ }^{16}$.

The Commission directed the attention of the government towards urban development sector with a much needed orientation to emerging environmental hazards. The recommendations of the N.C.U. have been accepted by the Government of India in principle. The Eight Five Year Plan document accordingly recognizes the approach of the N.C.U. towards urban development problems as a necessary step to bring desired changes. It is also evident from the significant increase from earlier plan allocations towards the urban development sector in the Eight Five Year Plan as indicated earlier. However, incorporations of the principles in the plan documents must be backed by positive steps of governmental machinery.

A major landmark in the development of urban policy in India is the formation of Jawaharlal Nehru National Urban Renewal Mission (JNNURM) in December 2005. It was a great assertion on the role of cities in economic development. The mission presented reforms comprising four schemes: funding for specific projects for urban infrastructure and basic urban services in 65 cities of India through two schemes, the Scheme for 
Urban Infrastructure and Governance and the Scheme for Basic Services to the Urban Poor. The other two schemes are Urban Infrastructure Development Scheme for Small and Medium Towns and the Integrated Housing and Slum Development Programme for the Urban Poor. JNNURM is a process of partnership between the Govt. of India and the Urban Local Bodies, which has to prepare a perspective plan or a City Development Plan. It is a major achievement to highlight the role of Indian cities in developing economic productivity and promoting efficient and inclusive growth of cities. The provision for the water sector accounts for the single largest share of the funds dispersed under the JNNURM for infrastructure development. It is an agenda for reform through the implementation of the $74^{\text {th }}$ constitutional amendment. In this context, two mandatory reforms for state governments are, Elections to the ULBs and transfer of the $12^{\text {th }}$ Schedule Functions to ULBs and the other is the Formation of District/ metropolitan Planning Committees. Under JNNURM the mandatory reforms for ULBs are Accounting Reforms, Property Tax Reforms, recovering User Charges, E-Governance Setup and provision of Urban Basic Services to the poor. It has been observed that the mission's approach has been successful in the more progressive states, e.g. in Andhra Pradesh, Karnataka, Gujarat, Maharastra and Tamil Nadu. In other states the implementation of Governance Reforms are not very effective so far ${ }^{17}$ (Sub Committee). A review of the reforms proposed under the Mission and other pro-liberalization documents makes it clear that these are designed largely to the benefit of domestic and international investors and elite residents in Indian cities. ${ }^{18}$ (Batra) As analyzed by Amitava Kundu ,Presently, a strong lobby is emerging, particularly in large cities, pleading for disbanding all zoning restrictions, building laws and bye-laws and making the cities relatively independent of state and central level controls. As a part of neo-liberal perspective, the urban structure in the country has become more top heavy as only these large cities and their immediate hinterland have absorbed most of the migrants. ${ }^{19}$ (Amitava Kundu, 2003)

\section{Conclusion: Neo liberal policy and urban reforms}

There is a reflection in urban development policy in India of some influencing trends in the political system itself, which are corollaries of economic development strategies in general. It started with the approach of regional development planning, continuing with ad hoc comprehensive development programmes along with the master plan approach; it took a formidable turn towards pro liberal economic policy with emphasis on market and external assistance. The neo liberal perspective is leading to a complicated situation with stress on some mutually contradictory aspects. The political system is now gearing up to meet the challenges of high growth rate of large cities with ever expanding economic role. Thus politics of urban development management has again been emphasized. Infrastructure development is a priority to attract the market. However the challenges of urban restructuring in the context of neo liberal policy reassert the needs of capacity building both at the planning and the ground level. In policy documents planned development of cities has always been prioritized. There was little attempt to reconcile the aim of making cities as generators of economic momentum with the consideration of complex realities of sustainable urban development. In this process there is a great danger of ever increased regional disparity and imbalanced provision for allocation of development assistance.

\section{References}

[1]. B.D. Raheja, Urban India and Public Policy, Somaiya publishers New Delhi, 1973, p. 7.

[2]. Lalit Batra, A review of Urbanization and urban policy in post-independent India, Working Paper Series, Centre for the Study of Law and Governance, Jawaharlal Nehru University, New Delhi, April 2009.

[3]. Urban Policy Reforms for India in V.K. Agnihotri, ed., Public Policy Analysis and Design, Concept Publishing Company, New Delhi, 1995, pp. 163-64.

[4]. B.D. Raheja, 1973. Op. cit

[5]. J.K. Gupta, Senior Town Planner, Punjab Development Authority, Chandigarh, Seminar Paper, made available by I.T.P.I. Journal, Vol. 17, No. 2, December 1998. p. 68-69.

[6]. ibid.

[7]. ibid

[8]. Abhijit Datta, Municipal Reform in India, Economic and Political Weekly, September, 23, 1995. p. 2395.

[9]. N.N. Som, Director of Planning, Calcutta Metropolitan Development Authority, paper in the $42^{\text {nd }}$ National Town and Country Planning Congress, Institute of Town Planners, New Delhi, 1995.

[10]. Subhasis Banerjee, Director, T\&CP., Bhopal, paper in $47^{\text {th }}$ National T\&CP Congress, Bhubaneshwar, 1998.

[11]. V.K.R.V. Rao, Rural Development and Urbanization (Essay) in Labour and Planning, ed. Radhakamal Mukherjee, Allied Publishers, Bombay, 1964, p. 225.

[12]. S.C Gupta S.C. Gupta, Sociology of Planning in India, Crown Publication, New Delhi, 1980. p. 130.

[13]. Task Force Report on "Housing and Urban Development", Planning Commission, New Delhi, September, 1983, introduction, pp. 115.

[14]. M.N. Buch, Environmental Consciousness and Urban Planning, Orient Longman, New Delhi, 1993, p. 62.

[15]. Report of the National Commission on Urbanization, Vol-1, Chapter-1, made available by M.N. Buch, ibid. p. 16.

[16]. ibid

[17]. Report on Sub-Committee on Financing urban infrastructure in $12^{\text {th }}$ plan, March 2012, Ministry of Urban Development, Govt. of India.

[18]. Lalit Batra, April 2009, op. cit.

[19]. Amitabh Kundu, Impact of Neo-Liberal Policies on Urban Morphology: IndianCasehttp://www.aerus.net/web/sat/workshops/2003/papers/docs/32.pdf. 